\title{
Correspondence
}

\section{Leg pains after spinal anaesthesia}

To the Editor:

Lately, $5 \%$ lidocaine hydrochloride with glucose $7.5 \%$ solution (hyperbaric or heavy lidocaine), when given through a spinal catheter, has been implicated with the cauda equina syndrome. ${ }^{1,2}$ Following these reports, hyperbaric lidocaine has been associated with leg pains after spinal anaesthesia with the patients in the lithotomy position. 3,4 The following case is presented to alert further anaesthetists of this complication.

A 67-yr-old woman weighing $70 \mathrm{~kg}$ with no significant medical history and receiving no concurrent drug therapy was to undergo cystoscopy. With the patient in the sitting position, lidocaine $1 \%$ solution, $2 \mathrm{ml}$, was infiltrated into the $\mathrm{L}_{3-4}$ interspace. Lumbar puncture was made on the first attempt with a Spinocan (Braun) 25-gauge needle. Hyperbaric lidocaine $2 \mathrm{ml}$ (Xylocaine heavy, Astra) was injected into the cerebo-spinal fluid and she was placed in the lithotomy position $45 \mathrm{sec}$ later. The level of analgesia reached the umbilicus (T-10). The 40-min surgical procedure was uneventful. When the sensory and motor blocks had recovered, her only complaint involved the urinary catheter. Twelve hours later the patient began complaining of bilateral pain in her thighs and legs extending to just above the ankles. The pains lasted two days and paracetomol po provided only limited relief.

It is perplexing why such complaints have appeared in the literature only recently. The few peripheral nerve symptoms described earlier were of motor weakness, hypoaesthesia or of paraesthesia. ${ }^{5}$ Perhaps anaesthetists have blamed the lithotomy position, as in the present case. Interestingly, in 1947, Dinsdale warned of the neurotoxic effects of a hyperbaric local anaesthetic solution (amylocaine) used for spinal anaesthesia in combination with the position of the patient. ${ }^{6}$ Although possible mechanisms for the muscle pains have been proposed, ${ }^{3,4}$ their cause remains unclear. Controlled clinical studies are needed to determine the future of hyperbaric local anaesthetic solutions. Until then, anaesthetists might consider avoiding the use of the solution in question.

Dimitri A. Cozanitis B Pharm MD DTM\&H

Department of Anaesthesia

University of Helsinki

00290 Helsinki, Finland
REFERENCES

1 Rigler $M L$, Drasner $K$, Krejcie TC, et al. Cauda equina syndrome after continuous spinal anesthesia. Anesth Analg 1991; 72: 275-81.

2 Schell RM, Brauer FS, Cole DJ, Applegate $R L$. Persistent sacral nerve root deficits after continuous spinal anaesthesia. Can J Anaesth 1991; 38: 908-11.

3 Schneider M, Ettlin T, Kaufmann M, et al. Anesth Analg 1993; 76: 1154-7.

4 Sjöström $S$, Bläss $J$. Severe pain in both legs after spinal anaesthesia with hyperbaric $5 \%$ lignocaine solution. Anaesthesia 1994; 49: 700-2.

5 Phillips $O C$, Ebner $H$, Nelson AT, Black $M H$. Neurologic complications following spinal anaesthesia with lidocaine: a prospective review of 10,440 cases. Anesthesiology 1969; 30: 284-9.

6 Dinsdale $T$. Spinal analgesia and cauda equina lesions. Anaesthesia 1947; 2: 17-27.

\section{Oxygen tank check}

To the Editor:

I would like to remind Canadian anaesthetists of the importance of an adequate preuse machine check that confirms the availability of tank oxygen sources.

Several reported incidents across Canada have reminded us that $\mathrm{O}_{2}$ supply failure for auxiliary tanks can occur even when there is $\mathrm{O}_{2}$ tank pressure. Most incidents to date have involved Drager Narkomed 2B machines that have an O-Ring valve between the tank cylinder supply and the pipeline supply which is designed to close off tank sources when pipeline pressure is available, and open when pipeline pressure falls. When the O-Rings age they become brittle and the valve fails to open. Regular servicing and replacing of the valve O-Rings is important in preventing the problem, but failures have occurred in machines that have had the manufacturer's recommended servicing.

The ultimate protection is to test the tank $\mathrm{O}_{2}$ supply in the morning preuse check. It is not good enough to turn on the tank valve and observe adequate pressure. Our recommended procedure is to disconnect the pipeline $\mathrm{O}_{2}$ and to demonstrate flow of $\mathrm{O}_{2}$ from the tanks, then to reconnect pipeline sources and turn off tank sources.

According to the manufacturer, O-Ring failure will not occur suddenly but develops over a number of months. By testing tank supplies regularly, developing $\mathrm{O}_{2}$ tank 